\title{
Preparation and Characterization of Polymer-Grafted Montmorillonite-Lignocellulose Nanocomposites by In Situ Intercalative Polymerization
}

\author{
Tavengwa Bunhu, ${ }^{1}$ Nhamo Chaukura, ${ }^{2}$ and Lilian Tichagwa ${ }^{1}$ \\ ${ }^{1}$ Department of Pure and Applied Chemistry, University of Fort Hare, Alice Campus, Private Bag X1314, Alice 5700, South Africa \\ ${ }^{2}$ Nanotechnology and Water Sustainability Research Unit, College of Engineering, Science and Technology, University of South Africa, \\ Johannesburg BE277, South Africa
}

Correspondence should be addressed to Nhamo Chaukura; nchaukura@gmail.com

Received 13 April 2016; Revised 9 July 2016; Accepted 11 July 2016

Academic Editor: Mariatti bt Jaafar

Copyright (C) 2016 Tavengwa Bunhu et al. This is an open access article distributed under the Creative Commons Attribution License, which permits unrestricted use, distribution, and reproduction in any medium, provided the original work is properly cited.

Lignocellulose-clay nanocomposites were synthesized using an in situ intercalative polymerization method at $60^{\circ} \mathrm{C}$ and a pressure of $1 \mathrm{~atm}$. The ratio of the montmorillonite clay to the lignocellulose ranged from 1:9 to 1:1 (MMT clay to lignocelluloses, wt\%). The adsorbent materials were characterized by Fourier transform infrared spectroscopy (FTIR), thermogravimetric analysis (TGA), transmission electron microscopy (TEM), and X-ray powder diffraction (XRD). FTIR results showed that the polymers were covalently attached to the nanoclay and the lignocellulose in the nanocomposites. Both TEM and XRD analysis showed that the morphology of the materials ranged from phase-separated to intercalated nanocomposite adsorbents. Improved thermal stability, attributable to the presence of nanoclay, was observed for all the nanocomposites. The nanocomposite materials prepared can potentially be used as adsorbents for the removal of pollutants in water treatment and purification.

\section{Introduction}

Nanotechnology based methods for water purification, if well developed, have the potential to produce highly purified water at low cost. Nanoadsorbents such as carbon nanotubes, zeolites, carbon nanotubes-supported cerium oxide, activated carbon fibres, alginate/carbon nanotubes composites, and layered double hydroxides have been investigated for the removal of pollutants ranging from heavy metals, dyes, and organics from aqueous systems [1]. Viruses and bacteria can also be removed from water using layered double hydroxides (LDH) nanocomposites with removal efficiency greater than $99 \%$ [2].

Use has been made of different types of nanocomposites for the removal of a wide array of pollutants from contaminated water. Such pollutants include nitrophenols [3], dyes [4], heavy metals [5, 6], perchlorate ions [7], and chlorinated organics [8]. Removal efficiencies of up to $99 \%$ were reported for various pollutants by different researchers.
Nanocomposites thus have the potential to give highly treated and pure waste water effluents. The major hindrance in the widespread application of nanotechnology, however, is the unavailability of a large quantity of nanomaterials at economically viable prices [1]. Therefore, the search for highly effective, efficient, and low-cost nanoadsorbent materials for water treatment and purification is an on-going challenge.

Lignocellulose and montmorillonite clay have been identified as low-cost and potentially effective adsorbent materials. Lignocellulose-montmorillonite clay nanocomposites have been widely studied for application in structural materials especially in the furniture and in the packaging industry. The relatively low-cost lignocellulose-clay nanocomposites can also be used as adsorbent materials for the removal of inorganic and organic pollutants from aqueous solutions. Being derived from biomass, the advantages include low density, low equipment abrasiveness, relatively low cost, and biodegradability. Montmorillonite (MMT) clay is a naturally occurring 2:1 phyllosilicate mineral which comes in powder 
form and when completely delaminated, approximately $1 \mathrm{~nm}$ thick platelets or sheets are obtained with surface areas of about $750 \mathrm{~m}^{2} / \mathrm{g}$ and an aspect ratio $>50$ in comparison to conventional microsized fillers [9].

Most lignocellulose-clay nanocomposites have been prepared using the melt intercalation method. Wang et al., 2003 [10], investigated the mechanical properties, water absorbency, and morphology of poly(propylene)/wood flour/ organophilic clay nanocomposites. Poly(ethylene-octene) elastomer-clay-wood flour nanocomposites prepared by melt blending showed an improvement in the mechanical and tensile strength and the thermal stability of the resultant nanocomposites was observed [11]. Poly[methylene-(polyphenyl isocyanate)], aminopropyltriethoxysilane, maleated polypropylene, and copper metallic complex have proved to be effective coupling agents for this composite system [12]. Zhao et al. [13] described the preparation of poly(vinyl chloride)/wood flour/montmorillonite nanocomposites and assessed the effects of coupling agents and amount of layered silicate. The nanocomposites were largely directed at structural materials like furniture boards and flooring materials.

In order to achieve a more porous material and unlock more surface area in the product, an in situ intercalative polymerization method was employed in the present study. It was also necessary to achieve covalent bonding of the polymer to both the lignocellulose and the clay to avoid leaching of the polymer (especially the water soluble polymers like poly(methacrylic acid)) into water to avoid secondary pollution problems. As such, the polymers served as swelling agents to trigger clay exfoliation and coupling agents, which served as bridges between the lignocellulose and the montmorillonite clay. The in situ intercalative polymerization method has not been widely applied in the preparation of wood-clay nanocomposites. The prepared nanocomposites were soxhlet-extracted with different organic solvents to remove any unreacted monomers. It is postulated that sodium montmorillonite (NaMMT) clay particles get covalently attached to lignocellulose to create some kind of a brush-like structure with the NaMMT particles sticking out for adsorption of pollutants from aqueous solution.

\section{Experimental}

Platanus $x$ hispanica (London plane) tree leaves were used as a source of lignocellulose. Powdered leaf biomass (lignocellulose) was soxhlet-extracted using a $1: 1(\mathrm{v} / \mathrm{v})$ ethanol: water solvent mixture and dried at $50^{\circ} \mathrm{C}$ for $48 \mathrm{~h}$. Sodiumexchanged montmorillonite (NaMMT) was prepared from montmorillonite nanoclay according to Carrado et al. [14]. All the chemical reagents were used as received.

Methyl methacrylate (MAA, 99\%) purchased from SAARCHEM (Pty) Ltd was distilled before use and methyl orange was used as received. Methacrylic acid and dibutyl tin dilaurate (DBTDL, 95\%) from Sigma-Aldrich were used as received. Methacryloxypropyltrimethoxysilane (MPS, 99\%), ammonium persulphate (AMPS, 98\%), and aluminium chloride hexahydrate (99\%) were from Associated Chemical Enterprises. Dodecylbenzylsulphonic acid (DBS) and sodium metabisulphite (SMBS, 95\%) were purchased from $\mathrm{BDH}$
Chemicals and sodium chloride salt (99.5\%) was from METU-ED CC.

2.1. Preparation of Poly(methyl methacrylate)-Grafted Lignocellulose-Montmorillonite Nanocomposite (PMMAgLigNaMMT). SMBS $\left(4.3 \times 10^{-5} \mathrm{~mol}\right)$ and DBS $\left(4.5 \times 10^{-5} \mathrm{~mol}\right)$ were dissolved in deionized water in a three-neck round bottom flask. Soxhlet-extracted lignocellulose was then added slowly to the mixture under high speed magnetic stirring, which was then followed by the slow addition of NaMMT. The mixture was stirred for $1 \mathrm{~h}$ to completely disperse the solids followed by the addition of MMA to form an emulsion. $\mathrm{N}_{2}$ gas was bubbled into the system to purge oxygen and was maintained till the end of the reaction. After mixing for a further $30 \mathrm{~min}$, AMPS (dissolved in $10 \mathrm{~mL}$ of deionized water) was added to the mixture and stirred for 30 min before refluxing the mixture at $60^{\circ} \mathrm{C}$ under $\mathrm{N}_{2}$ for $4 \mathrm{~h}$. The mixture was cooled to room temperature, and the product (PMMAgLig-NaMMT) was isolated by filtration, followed by purification by solvent extraction with THF $(20 \mathrm{~mL})$ to remove PMMA homopolymer, and dried at $50^{\circ} \mathrm{C}$ for $24 \mathrm{~h}$. The materials were prepared at different compositions of montmorillonite ranging from 10 to $50 \% \mathrm{w} / \mathrm{w}$ for all nanocomposite adsorbents. However, the results reported are only for the sample prepared at $40 \% \mathrm{w} / \mathrm{w}$.

\subsection{Preparation of Poly(methacryloxypropyltrimethoxysilane)-} Coupled Lignocellulose-Montmorillonite Nanocomposite (PMPSgLig-NaMMT). Soxhlet-extracted lignocellulose $(3.0 \mathrm{~g})$ and NaMMT $(3.0 \mathrm{~g})$ were dispersed in a $1: 1 \mathrm{v} / \mathrm{v}$ EtOH $: \mathrm{H}_{2} \mathrm{O}$ solvent $(150 \mathrm{~mL})$ mixture under high speed magnetic stirring for $1 \mathrm{~h}$. MPS $\left(1.4 \times 10^{-2} \mathrm{~mol}\right)$ was added to the lignocellulose-NaMMT dispersion and mixed for $10 \mathrm{~min}$. A catalyst, dibutyl tin dilaurate $\left(2.1 \times 10^{-4} \mathrm{~mol}\right)$, was added and the mixture stirred for $10 \mathrm{~min}$. The mixture was then heated to $70^{\circ} \mathrm{C}$ and left to react at this temperature for $24 \mathrm{~h}$.

After $24 \mathrm{~h}$, the mixture was cooled to room temperature and the MPS-coupled lignocellulose-montmorillonite (PMPSgLig-NaMMT) nanocomposite isolated by filtration. THF was used as solvent in soxhlet extraction for $24 \mathrm{~h}$ to remove the free MPS monomer, the homopolymerized silane, and the catalyst. The same NaMMT clay loading to lignocellulose of 10 to $50 \% \mathrm{w} / \mathrm{w}$ was used. The PMPSgLig-NaMMT nanocomposite was dried at $50^{\circ} \mathrm{C}$ for $24 \mathrm{~h}$. The sample was characterized by FTIR, TGA, XRD, and TEM and the results at $40 \% \mathrm{w} / \mathrm{w}$ NaMMT loading were reported.

\subsection{Preparation of Poly(methacrylic acid)-Grafted Lignocellu-} lose-Montmorillonite Nanocomposites (PMAAgLig-NaMMT). PMAA-grafted lignocellulose-montmorillonite (PMAAgLigNaMMT) nanocomposites were prepared at different montmorillonite clay loadings. The required amount of MPSgrafted lignocellulose was slowly dispersed in deionized water $(150 \mathrm{~mL})$ to which ethanol $(5 \mathrm{~mL})$ had been added. The ethanol was added to improve the dispersion of both the MPS-grafted lignocellulose and MPSgMMT in the water. After all the solids had been homogeneously dispersed in the water (about $1 \mathrm{~h}$ ), MAA was added and mixed for $30 \mathrm{~min}$, 
followed by the addition of AMPS. The AMPS was first dissolved in deionized water $(10 \mathrm{~mL})$ before being added to the mixture. The system was heated to $70^{\circ} \mathrm{C}$ under $\mathrm{N}_{2}$ atmosphere to initiate the graft polymerization reaction, and the temperature was maintained for $24 \mathrm{~h}$, after which the mixture was cooled to room temperature and the product (PMAAgLigNaMMT) isolated by filtration. The NaMMT clay loading to lignocellulose of 10 to $50 \% \mathrm{w} / \mathrm{w}$ was used. The product was washed with $0.01 \mathrm{M} \mathrm{NaOH}$ solution and then deionized water until the filtrate was at $\mathrm{pH} 5$. The product was further soxhletextracted with THF for $24 \mathrm{~h}$ in order to remove all PMAA homopolymer and then dried at $50^{\circ} \mathrm{C}$ for $24 \mathrm{~h}$. The nanocomposites were characterized by FTIR, TGA, XRD, and TEM and results for the $40 \% \mathrm{w} / \mathrm{w}$ NaMMT loading were reported.

2.4. Characterization. FTIR analysis was performed (PerkinElmer, 2000) using the procedure described by Rajendran et al., 2001 [15]. A thermogravimetric analyzer (PerkinElmer, TGA7) fitted with a thermal analysis controller (TAC7/DX) was used for thermogravimetric analysis. The instrument was operated under $\mathrm{N}_{2}$ atmosphere and the samples were heated from $20^{\circ} \mathrm{C}$ to $900^{\circ} \mathrm{C}$ at a heating rate of $15^{\circ} \mathrm{C} /$ minute. XRD measurements were carried out in locked couple mode with a Bruker AXS D8 Advance diffractometer $(\mathrm{Cu} \mathrm{K} \alpha$ radiation with $\lambda=1.5406 \AA, 40 \mathrm{kV}, 40 \mathrm{~mA}$ ) equipped with a PSD Lynx-Eye Si-strip detector (with 196 channels), at room temperature.

TEM images were recorded on a JEM 200CX transmission electron microscope (JEOL, Tokyo, Japan) at an accelerating voltage of $120 \mathrm{kV}$. Prior to analysis, the nanocomposites were stained with $\mathrm{OsO}_{4}$, then embedded in epoxy resin, and cured for $24 \mathrm{~h}$ at $60^{\circ} \mathrm{C}$. The embedded samples were then ultramicrotomed with a diamond knife on a Reichert Ultracut $S$ ultramicrotome at room temperature to give sections about $100 \mathrm{~nm}$ thick. The sections were transferred from water at room temperature to 300-mesh copper grids, which were then transferred to the TEM instrument. The results reported are for the nanocomposites prepared at a NaMMT clay loading of $40 \%$.

\section{Results and Discussion}

\subsection{Poly(methyl methacrylate)-Grafted Lignocellulose-Clay Nanocomposite (PMMAgLig-NaMMT)}

3.1.1. FTIR Analysis. The presence of the peak at $1734 \mathrm{~cm}^{-1}$ $(\mathrm{C}=\mathrm{O}$ of the ester linkage of PMMA) (Figure 1(a)) after soxhlet extraction of the sample using THF showed that the grafting reaction had been successful. In a related study on organosilanes, Castellano et al. [16] obtained similar results. The presence of the NaMMT in the nanocomposite was shown by the presence of the peaks at $468 \mathrm{~cm}^{-1}$ and $530 \mathrm{~cm}^{-1}$ which were ascribed to $\mathrm{Si}-\mathrm{O}-\mathrm{Si}$ and $\mathrm{Al}-\mathrm{O}-\mathrm{Si}$, respectively. The soxhlet extraction was necessary in order to open up the spaces in the nanocomposite which would act as adsorption sites for both heavy metals and organic pollutants.

3.1.2. Thermogravimetric Analysis. The presence of NaMMT in the lignocellulose matrix resulted in an increased thermal stability of the nanocomposite (Figure 1(b)). The raw lignocellulose showed a degradation of temperature of about $344^{\circ} \mathrm{C}$ whereas the nanocomposite showed a decomposition of temperature of about $375^{\circ} \mathrm{C}$. The $\%$ mass loss decreased with increase in amount of NaMMT in the nanocomposites. For the nanocomposites prepared with increasing amounts of NaMMT, the thermograms showed that the more the amount of NaMMT, the greater the thermal stability of the nanocomposites (results not shown). A similar trend in thermal stability was observed for the other types of nanocomposites (PMPSgLig-NaMMT and PMAAgLig-NaMMT). The amount of NaMMT in the nanocomposites could also be determined from the ash that remained after heating the samples to $900^{\circ} \mathrm{C}$, and this roughly corresponded with the amount of NaMMT in the nanocomposite.

3.1.3. X-Ray Diffraction. A slight shift of the basal reflection peak to lower $2 \theta$ angles (an increase in the $d$-spacing) was observed (Figure 1(c)). The basal reflection peak of montmorillonite shifted from $6.22^{\circ}$ (NaMMT) to $5.88^{\circ}$ for the PMMAgrafted nanocomposite. This corresponded to a $d$-spacing of $15.02^{\circ}$ for the nanocomposite from $14.20^{\circ}$ (NaMMT). This suggests that there was some partial intercalation of the poly(methyl methacrylate) into the interlayer space of the clay sheets.

3.1.4. Transmission Electron Microscopy. The micrograph showed that the NaMMT was dispersed in the lignocellulose matrix at nanoscale (Figure 1(d)). However, the clay sheets are still quite ordered, confirming the findings from the XRD data. It can be suggested that the product formed was an intercalated nanocomposite.

\subsection{Polymethacryloxypropyltrimethoxysilane-Grafted Lignocellulose-Montmorillonite Nanocomposites (PMPSgLig-NaMMT)}

3.2.1. FTIR Analysis. The FTIR spectrum for PMPSgLigNaMMT prepared at a NaMMT loading of $40 \%$ is shown in Figure 2(a). The $\mathrm{C}=\mathrm{C}$ stretching vibration peak of the nanocomposite was superimposed over that of the $\mathrm{H}-\mathrm{O}-\mathrm{H}$ bending vibration $\left(1635 \mathrm{~cm}^{-1}\right)$ of adsorbed water molecules (Figure 2(a)). The peaks at 2960 and $2930 \mathrm{~cm}^{-1}$ in the nanocomposite were ascribed to methylene $-\mathrm{CH}_{2}$-asymmetric and $-\mathrm{CH}_{2}$-symmetric stretching vibrations, respectively. The presence of the band at $1724 \mathrm{~cm}^{-1}(\mathrm{C}=\mathrm{O}$ stretching vibration of the ester group) in the nanocomposite after soxhlet extraction with THF showed that the grafting and/or coupling of lignocellulose and NaMMT was successful.

3.2.2. Thermogravimetric Analysis. The nanocomposite was more thermally stable compared with the raw lignocellulose, but less stable relative to the NaMMT (Figure 2(b)). The nanocomposite showed a degradation temperature of $425^{\circ} \mathrm{C}$ compared with $343^{\circ} \mathrm{C}$ for the raw lignocellulose. The increased thermal stability can be attributed to the presence of clay in the lignocellulose matrix [11]. The TGA thermogram 


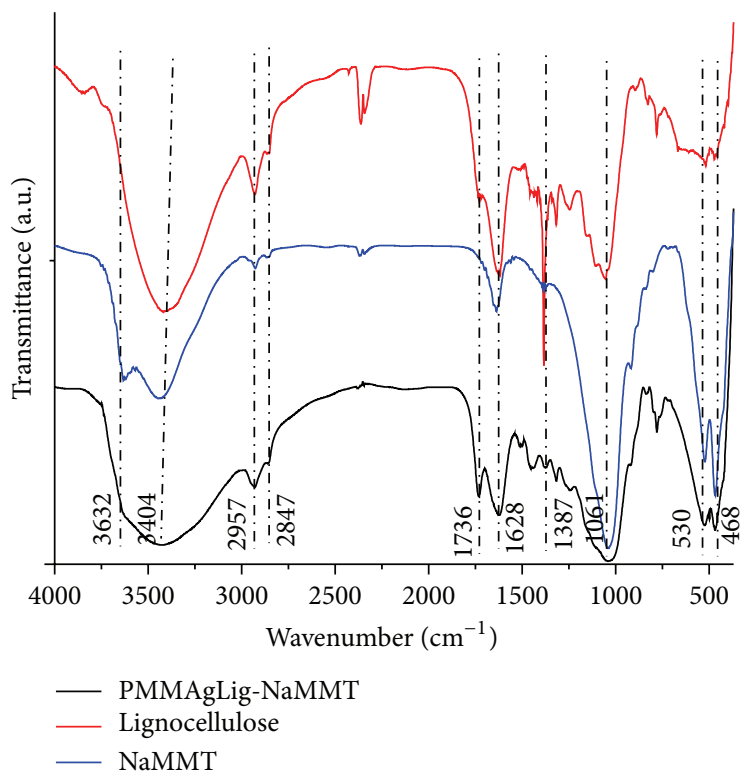

(a)

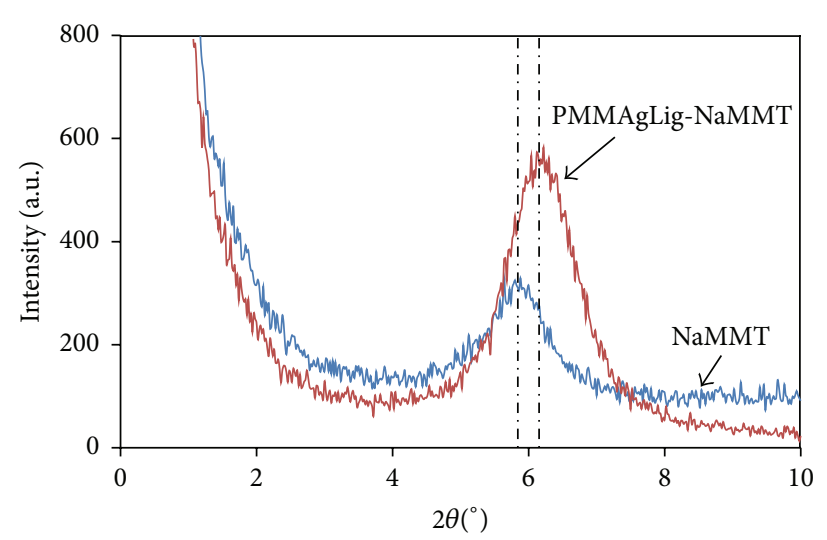

(c)

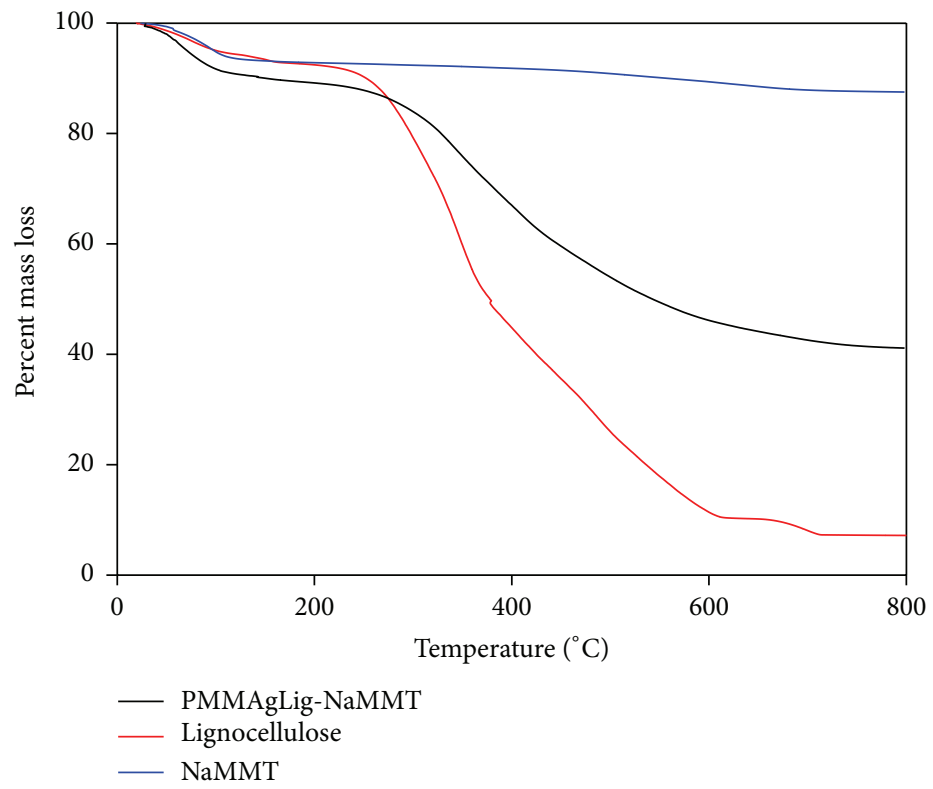

(b)

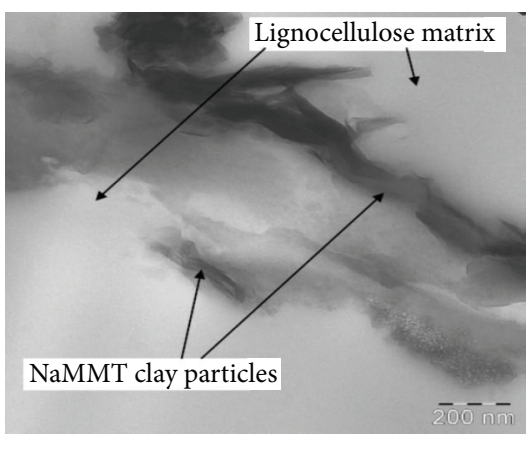

(d)

FIgURE 1: (a) FTIR spectra of raw lignocellulose, NaMMT, and PMMAgLig-NaMMT nanocomposite. (b) TGA thermograms of NaMMT, raw lignocellulose, and PMMAgLig-NaMMT. (c) X-ray diffractograms of NaMMT and PMMAgLig-NaMMT. (d) Transmission electron micrograph of PMMAgLig-NaMMT nanocomposite.

and the FTIR spectrum of the MPS-grafted lignocellulosemontmorillonite nanocomposite show NaMMT was incorporated into the lignocellulose matrix.

3.2.3. X-Ray Powder Diffraction Analysis. There was a shift in the montmorillonite basal reflection peak towards lower $2 \theta$ angles for the PMPSgLig-NaMMT (Figure 2(c)). This shift might be as a result of partial intercalation and polymerization of the MPS in the interlayer galleries of the NaMMT. The $d$-spacing increased from 14.20 (NaMMT) to $15.12 \AA$ for the nanocomposite. The XRD patterns show that the NaMMT clay sheets are still ordered in the nanocomposite as judged from the intensity of the basal reflection peak as well as the $d$-spacing. This might suggest an intercalated nanocomposite or a microcomposite (phase-separated).
3.2.4. Transmission Electron Microscopy. The micrograph of PMPSgLig-NaMMT (Figure 2(d)) shows some clay aggregates as well as nanometer-sized clay particles dispersed in the lignocellulose matrix. This suggests that the dispersion of the clay particles was not homogeneous, thus giving a phaseseparated composite [17-19].

\subsection{Poly(methacrylic acid)-Coupled Lignocellulose-MMT Nanocomposites (PMAAgLig-NaMMT)}

3.3.1. FTIR Analysis. The PMAA-grafted nanocomposite (PMAAgLig-NaMMT) sample was prepared at a NaMMT loading of $40 \%$. The PMAAgLig-NaMMT spectrum showed an additional peak at $1268 \mathrm{~cm}^{-1}$ (Figure 3(a)) which was assigned to $\mathrm{C}-\mathrm{O}$ stretching vibration coupled with $\mathrm{O}-\mathrm{H}$ 


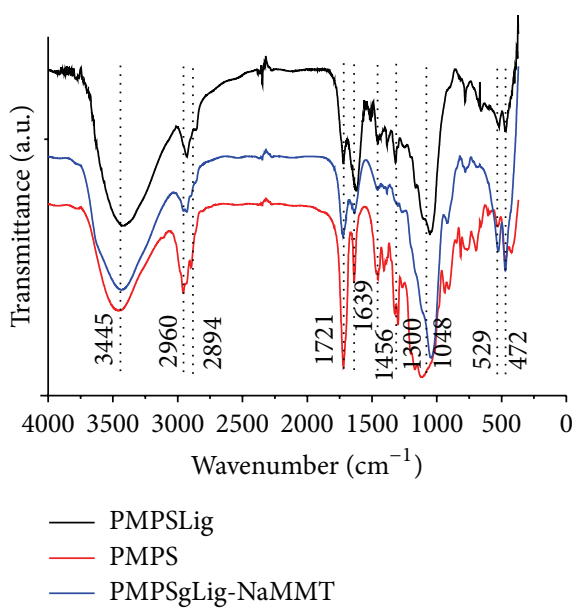

(a)

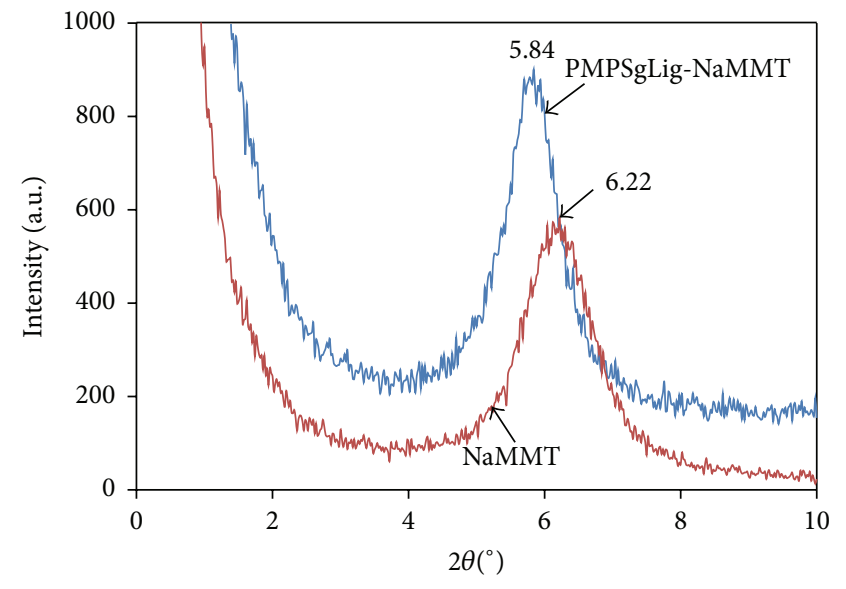

(c)

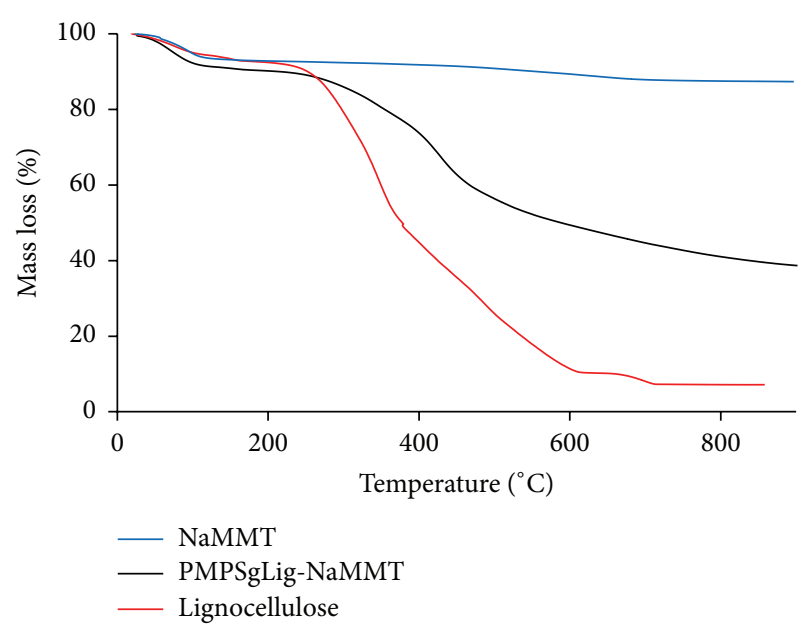

(b)

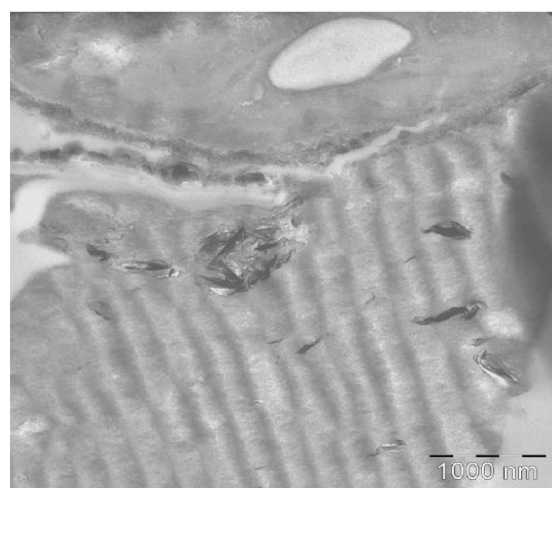

(d)

FIGURE 2: (a) FTIR spectra of PMPS and PMPS-grafted lignocellulose-MMT nanocomposite. (b) Thermograms of raw lignocellulose, NaMMT, and PMPS-grafted lignocellulose-montmorillonite nanocomposite. (c) XRD patterns of NaMMT and PMPS-grafted lignocelluloseNaMMT nanocomposite. (d) Transmission electron micrograph of PMPSgLig-NaMMT nanocomposite.

in-plane bending, associated with the $-\mathrm{COOH}$ dimer $[20$, 21]. This peak is also present in the spectrum for PMAA. Another peak associated with the presence of the PMAA in the nanocomposite can be seen at $2576 \mathrm{~cm}^{-1}$ (O-H stretching vibration carboxylic acid dimers [22] from the grafted PMAA). There was a shift of the $\mathrm{C}=\mathrm{O}$ stretching vibration peak to higher frequencies in the nanocomposite. This might be a result of the loss of $\mathrm{C}=\mathrm{C}$ bonds as MAA units reacted with the $\mathrm{C}=\mathrm{C}$ groups of the grafted MPS, resulting in a saturated ester linkage.

The structural $\mathrm{OH}$ stretching vibration $\left(3646 \mathrm{~cm}^{-1}\right)$ of the MMT was not very visible in the nanocomposite possibly because of the presence of hydrogen bonded $\mathrm{OH}$ groups from the lignocellulose.

3.3.2. Thermogravimetric Analysis. The PMAAgLig-NaMMT sample prepared at a NaMMT loading of $40 \%$ showed three decomposition steps at temperatures $30-120^{\circ} \mathrm{C}, 220-$ $420^{\circ} \mathrm{C}$, and $420-650^{\circ} \mathrm{C}$ (Figure $3(\mathrm{~b})$ ). The decomposition steps corresponded to loss of water, decomposition of lignocellulose together with the grafted polymers to form char, and decomposition of the solid residue (char), respectively. A greater thermal stability was recorded for the nanocomposite compared to the MPS-grafted lignocellulose. The \% mass loss increased in the order PMPSgMMT < PMAAgLig-NaMMT $<$ PMPSgLig. The higher thermal stability shown by the nanocomposite can be attributed to the presence of NaMMT dispersed in the lignocellulose matrix. A summary of the thermal properties for the synthesized materials (Table 1) shows them to be thermally more robust than lignocellulose, suggesting the synthesized materials can potentially be used at high temperatures.

3.3.3. X-Ray Powder Diffraction Analysis. The X-ray diffractograms of NaMMT and PMAAgLig-NaMMT nanocomposite showed a shift of the basal reflection peak to lower $2 \theta$ angles. The $d$-spacing increased from 14.20 to $15.47 \AA$, showing some opening up of the nanoclay sheets. The nanocomposite obtained had partially intercalated nanoclay sheets. 
TABLE 1: Summary of thermal properties of synthesized materials compared to the precursors.

\begin{tabular}{|c|c|c|c|}
\hline Material & $\begin{array}{l}\text { Onset temperature } \\
\qquad\left({ }^{\circ} \mathrm{C}\right)\end{array}$ & $\begin{array}{l}\text { Degradation } \\
\text { temperature } \\
\left({ }^{\circ} \mathrm{C}\right)\end{array}$ & Remarks \\
\hline PMPSgLig-NaMMT & 220 & $220-650$ & $\begin{array}{l}\text { Loss of water at } 30-120^{\circ} \mathrm{C} \text {; gradual degradation, showing } \\
\text { decomposition of lignocellulose at } 400^{\circ} \mathrm{C}\end{array}$ \\
\hline PMPSgLig-NaMMT & 320 & $425-900$ & Loss of water at $30-120^{\circ} \mathrm{C}$; gradual degradation \\
\hline PMAAgLi-NaMMT & 240 & $240-600$ & $\begin{array}{c}\text { Loss of water at } 30-120^{\circ} \mathrm{C} \text {; decomposition of lignocelluloses at } \\
220-420^{\circ} \mathrm{C} \text {, decomposition of grafted polymer at } 420-650^{\circ} \mathrm{C} \text {; gradual } \\
\text { degradation }\end{array}$ \\
\hline NaMMT & 220 & - & $\begin{array}{l}\text { Thermally stable within the analytical temperature range used; only } \\
\text { lost moisture around } 100-120^{\circ} \mathrm{C} \text { and water of crystallization }\end{array}$ \\
\hline Lignocellulose & 220 & $340-600$ & Loss of water at $30-120^{\circ} \mathrm{C}$; fairly rapid degradation \\
\hline
\end{tabular}

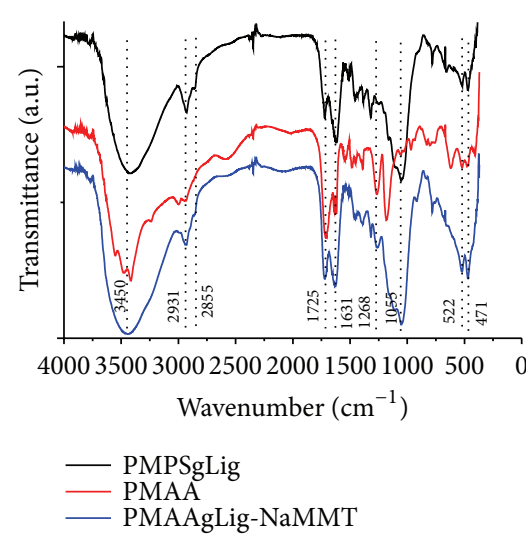

(a)

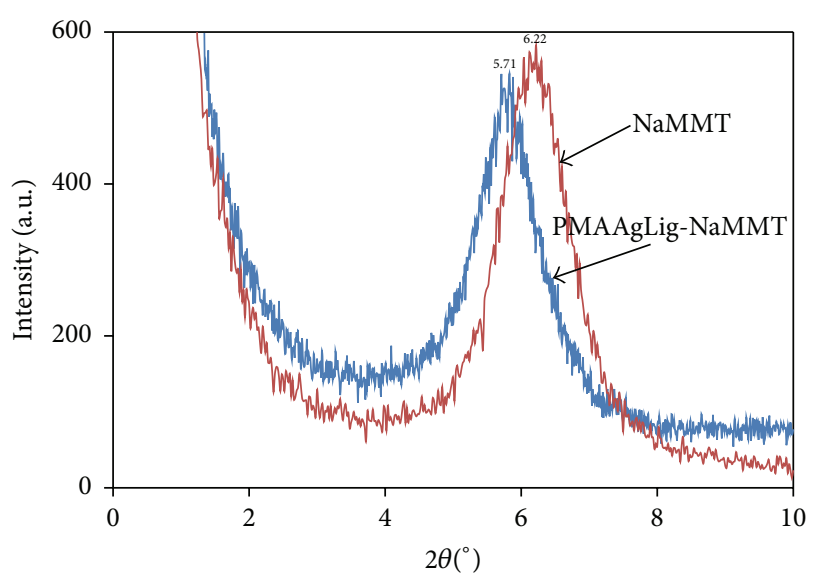

(c)

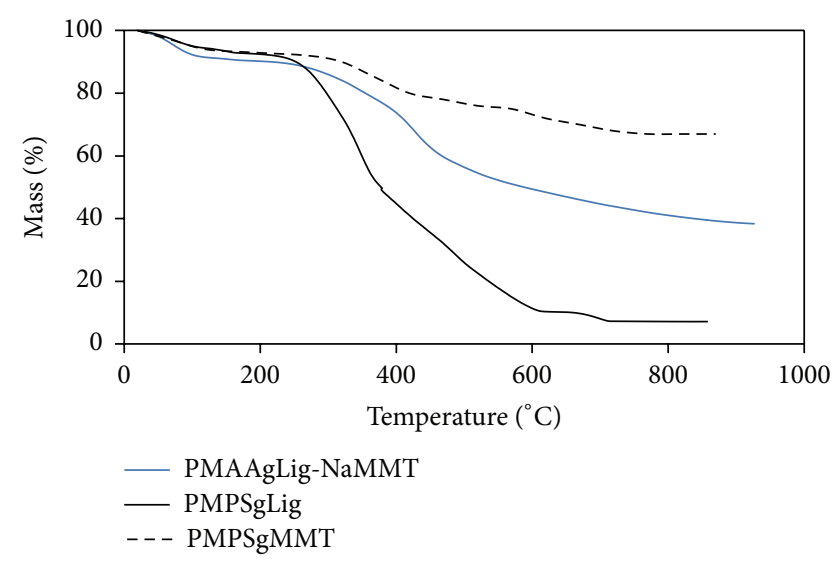

(b)

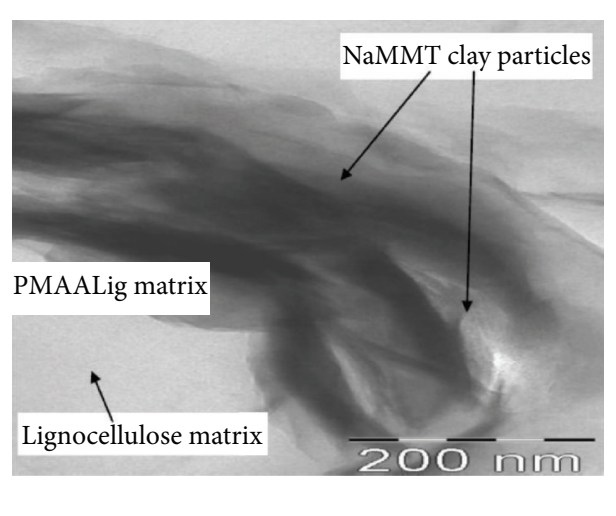

(d)

FIGURE 3: (a) FTIR spectra of PMAA, MPS-grafted lignocellulose, and PMAA-coupled lignocellulose-NaMMT nanocomposite. (b) TGA thermograms of MPSgMMT, MPSgLig, and PMAA-grafted lignocellulose-MMT nanocomposite. (c) XRD patterns of NaMMT and PMAAgLig-NaMMT. (d) Transmission electron micrograph of PMAAgLig-NaMMT nanocomposite.

3.3.4. Transmission Electron Microscopy. TEM showed the NaMMT still fairly ordered within the lignocellulose matrix (Figure 3(d)). The PMAAgLig-NaMMT morphology was comparable to that of PMMAgLig-NaMMT. However, relatively poor clay dispersion was observed for the
PMAAgLig-NaMMT nanocomposite compared with PMMAgLig-NaMMT in Figure 1(d) which showed distinct NaMMT clay particles. The TEM results confirm the observations made from the XRD results which also showed a highly ordered, partially intercalated clay structure in the 
nanocomposite. The clay particles displayed some long-range order, indicating the presence of strong van der Waals forces between the clay sheets.

\section{Conclusion}

Novel adsorbent materials (PMMAgLig-MMT nanocomposite, PMAAgMMT, PMAAgLig, PMPSgLig-MMT, and PMAAgLig-MMT nanocomposite) were prepared through condensation as well as free-radical graft polymerization reactions. The intended modification of the lignocellulose and MMT separately was achieved as confirmed by FTIR, TGA, and XRD. XRD analysis showed some partial intercalation of MMA into the interlayer space of the clay sheets. The nanocomposite adsorbents also showed a slight increase in the basal spacing of the MMT clay sheets. Intercalated nanocomposite adsorbent materials were successfully prepared as shown by FTIR, TGA, and XRD. Modification of lignocellulose with MPS resulted in improved thermal stability. All the nanocomposites prepared also showed an increase in thermal stability, which was attributed to the presence of clay in the lignocellulose matrix. However, modification of lignocellulose with PMMA resulted in a reduction in thermal stability. The nanocomposite materials prepared can potentially be used as adsorbents for the removal of pollutants in water treatment and purification.

\section{Disclosure}

Now Tavengwa Bunhu's affiliation is Chinhoyi University of Technology, Private Bag 7724, Chinhoyi, Zimbabwe, and Lilian Tichagwa's affiliation is Harare Institute of Technology, P.O. Box BE277, Belvedere, Harare, Zimbabwe.

\section{Competing Interests}

The authors declare that they have no competing interests.

\section{References}

[1] N. Savage and M. S. Diallo, "Nanomaterials and water purification: opportunities and challenges," Journal of Nanoparticle Research, vol. 7, no. 4-5, pp. 331-342, 2005.

[2] S. Jin, P. H. Fallgren, J. M. Morris, and Q. Chen, "Removal of bacteria and viruses from waters using layered double hydroxide nanocomposites," Science and Technology of Advanced Materials, vol. 8, no. 1-2, pp. 67-70, 2007.

[3] K. L. Salipira, B. B. Mamba, R. W. Krause, T. J. Malefetse, and S. H. Durbach, "Carbon nanotubes and cyclodextrin polymers for removing organic pollutants from water," Environmental Chemistry Letters, vol. 5, no. 1, pp. 13-17, 2007.

[4] L. Wang and A. Wang, "Adsorption characteristics of Congo Red onto the chitosan/montmorillonite nanocomposite," Journal of Hazardous Materials, vol. 147, no. 3, pp. 979-985, 2007.

[5] C. L. Ake, K. Mayura, H. Huebner, G. R. Bratton, and T. D. Phillips, "Development of porous clay-based composites for the sorption of lead from water," Journal of Toxicology and Environmental Health-Part A, vol. 63, no. 6, pp. 459-475, 2001.
[6] R. A. Khaydarov, R. R. Khaydarov, and O. Gapurova, "Water purification from metal ions using carbon nanoparticleconjugated polymer nanocomposites," Water Research, vol. 44, no. 6, pp. 1927-1933, 2010.

[7] Y. Lin, X. Cui, and J. Bontha, "Electrically controlled anion exchange based on polypyrrole and carbon nanotubes nanocomposite for perchlorate removal," Environmental Science and Technology, vol. 40, no. 12, pp. 4004-4009, 2006.

[8] C. L. Ake, M. C. Wiles, H. J. Huebner et al., "Porous organoclay composite for the sorption of polycyclic aromatic hydrocarbons and pentachlorophenol from groundwater," Chemosphere, vol. 51, no. 9, pp. 835-844, 2003.

[9] H. Kharbas, P. Nelson, M. Yuan, S. Gong, L.-S. Turng, and R. Spindler, "Effects of nano-fillers and process conditions on the microstructure and mechanical properties of microcellular injection molded polyamide nanocomposites," Polymer Composites, vol. 24, no. 6, pp. 655-671, 2003.

[10] S. Wang, Y. Hu, Q. Zhongkai, Z. Wang, Z. Chen, and W. Fan, "Preparation and flammability properties of polyethylene/clay nanocomposites by melt intercalation method from $\mathrm{Na}^{+}$montmorillonite," Materials Letters, vol. 57, no. 18, pp. 2675-2678, 2003.

[11] H.-T. Liao and C.-S. Wu, "Preparation of poly(ethyleneoctene) elastomer/clay/wood flour nanocomposites by a melting method," Macromolecular Materials and Engineering, vol. 290, no. 7, pp. 695-703, 2005.

[12] G. Sui, M. A. Fuqua, C. A. Ulven, and W. H. Zhong, "A plant fiber reinforced polymer composite prepared by a twin-screw extruder," Bioresource Technology, vol. 100, no. 3, pp. 1246-1251, 2009.

[13] Y. Zhao, K. Wang, F. Zhu, P. Xue, and M. Jia, "Properties of poly(vinyl chloride)/wood flour/montmorillonite composites: effects of coupling agents and layered silicate," Polymer Degradation and Stability, vol. 91, no. 12, pp. 2874-2883, 2006.

[14] K. A. Carrado, A. Decarreu, S. Petit, F. Bergaya, and G. Lagaly, "Synthetic clay minerals and purification of natural clays," in Handbook of Clay Science, Elsevier, 2006.

[15] S. Rajendran, R. Kannan, and O. Mahendran, "An electrochemical investigation on PMMA/PVdF blend-based polymer electrolytes," Materials Letters, vol. 49, no. 3-4, pp. 172-179, 2001.

[16] M. Castellano, A. Gandini, P. Fabbri, and M. N. Belgacem, "Modification of cellulose fibres with organosilanes: under what conditions does coupling occur?" Journal of Colloid and Interface Science, vol. 273, no. 2, pp. 505-511, 2004.

[17] M. Alexandre and P. Dubois, "Polymer-layered silicate nanocomposites: preparation, properties and uses of a new class of materials," Materials Science and Engineering R: Reports, vol. 28, no. 1, pp. 1-63, 2000.

[18] K. M. Dean, S. A. Bateman, and R. Simons, "A comparative study of UV active silane-grafted and ion-exchanged organoclay for application in photocurable urethane acrylate nanoand micro-composites," Polymer, vol. 48, no. 8, pp. 2231-2240, 2007.

[19] A. Di Gianni, E. Amerio, O. Monticelli, and R. Bongiovanni, "Preparation of polymer/clay mineral nanocomposites via dispersion of silylated montmorillonite in a UV curable epoxy matrix," Applied Clay Science, vol. 42, no. 1-2, pp. 116-124, 2008.

[20] J. Dong, Y. Ozaki, and K. Nakashima, FTIR Studies of Conformational Energies of Poly(Acrylic Acid) in Cast Films, John Wiley \& Sons, London, UK, 1997. 
[21] G. Polacco, M. G. Cascone, L. Petarca, and A. Peretti, "Thermal behaviour of poly(methacrylic acid)/poly( $N$-vinyl-2pyrrolidone) complexes," European Polymer Journal, vol. 36, no. 12, pp. 2541-2544, 2000.

[22] R. Erhardt, M. Zhang, A. Böker et al., "Amphiphilic Janus micelles with polystyrene and poly(methacrylic acid) hemispheres," Journal of the American Chemical Society, vol. 125, no. 11, pp. 3260-3267, 2003. 

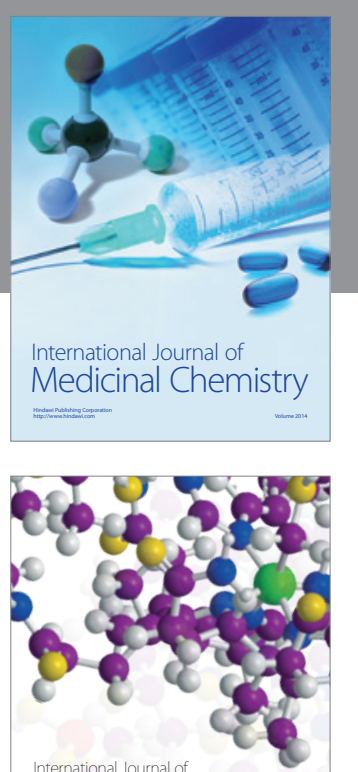

Carbohydrate Chemistry

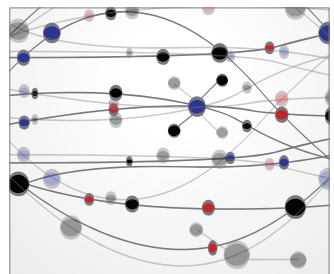

The Scientific World Journal
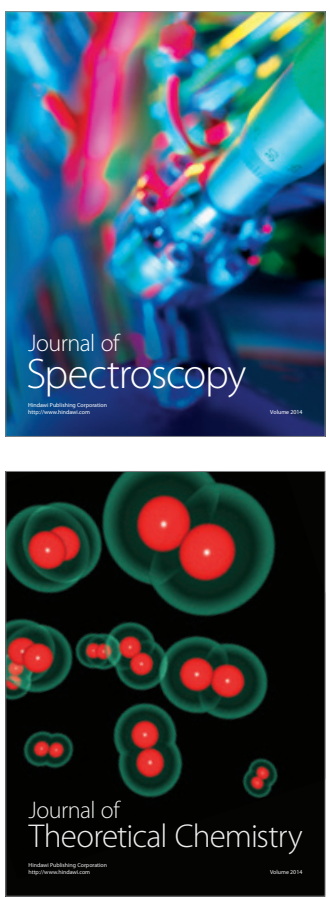
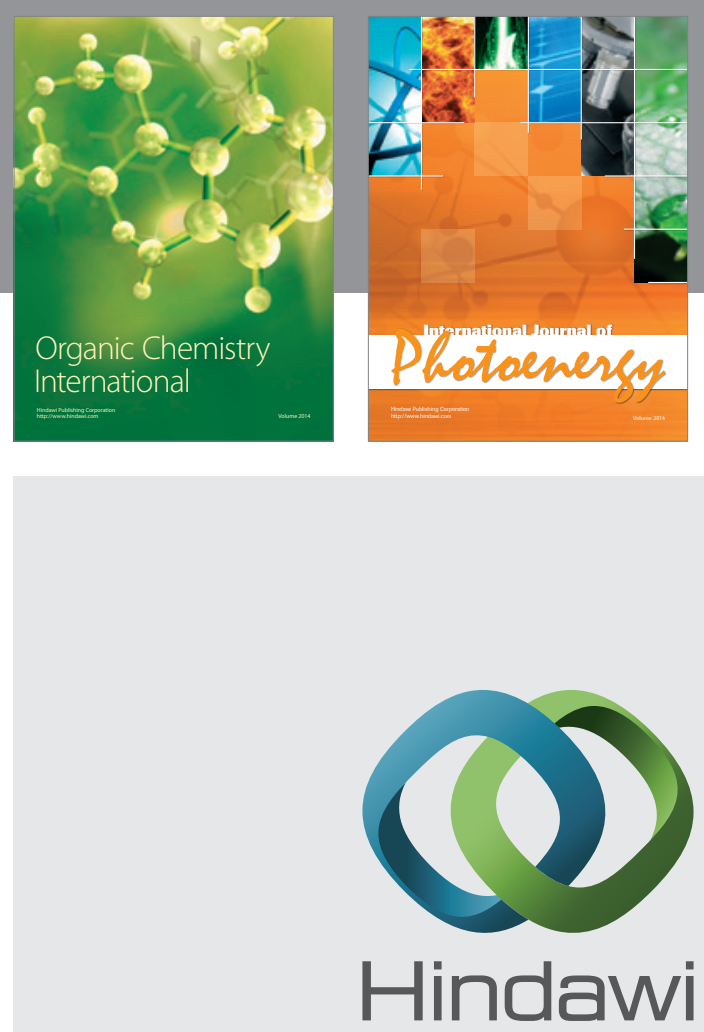

Submit your manuscripts at

http://www.hindawi.com

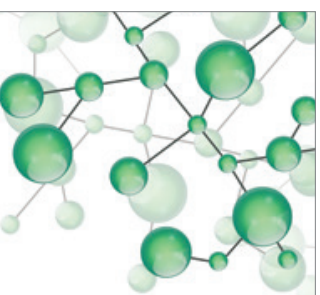

International Journal of

Inorganic Chemistry

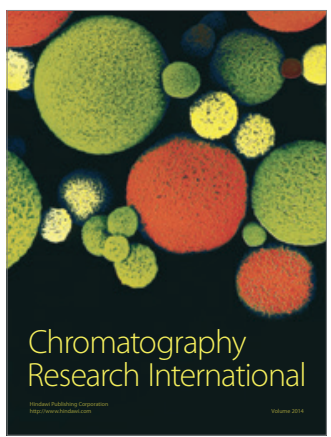

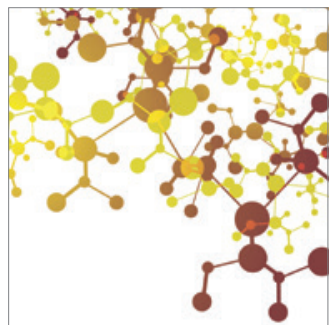

Applied Chemistry
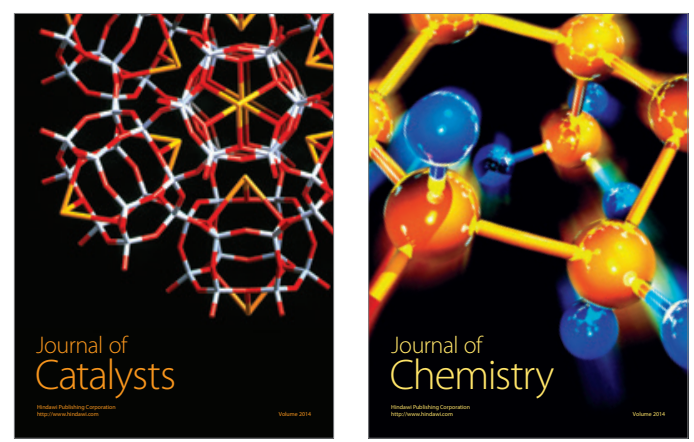
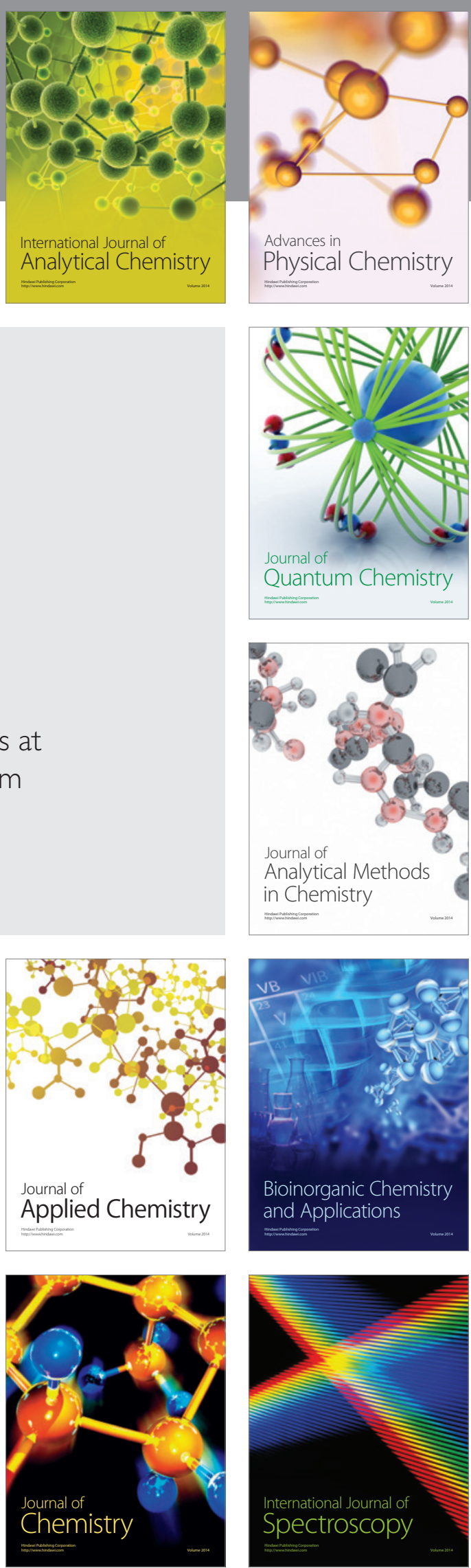